\title{
Novo gênero e espécie de Blattellidae (Blattaria) da Região Amazônica, Brasil
}

\author{
Sonia Maria Lopes \& Edivar Heeren de Oliveira
}

Departamento de Entomologia, Museu Nacional, Universidade Federal do Rio de Janeiro, Quinta da Boa Vista, 20940-040 São Cristóvão, Rio de Janeiro, Brasil. (sonialfraga@gmail.com)

\begin{abstract}
A new genus and species of Blattellidae (Blattaria) from Amazon Region, Brazil. A new genus (Chorisomaculata), similar to Chorisoneura Brunner, 1865 with a new species (Chorisomaculata manauensis) from state of Amazonas are described. The male genitalia is illustrated.
\end{abstract}

KEYWORDS. Chorisomaculata gen. nov., Amazonas, taxonomy, Neotropical.

RESUMO. Descreve-se um novo gênero (Chorisomaculata), similar a Chorisoneura Brunner, 1865 e uma nova espécie (Chorisomaculata manauensis) do estado do Amazonas. A genitália do macho é ilustrada.

PALAVRAS-CHAVE. Chorisomaculata gen. nov., Amazonas, taxonomia, Neotropical.

Neste trabalho é acrescentado aos blatelídeos um gênero novo e respectiva espécie com base em caracteres morfológicos. A família Blattellidae conta atualmente com 139 gêneros (BECCALONI, 2007) e se encontra dividida em seis subfamílias. O gênero aqui descrito apresenta caracteres genitais relacionados aos indivíduos pertencentes à subfamília Pseudophyllodromiinae, com 63 gêneros os quais têm aparência variável, nas fêmeas antes da oviposição não apresentam rotação da ooteca e nos machos possuem o falômero, em forma de gancho, disposto do lado direito do conjunto genital. Em relação à estrutura do proventrículo, nessa subfamília, a configuração das estruturas internas apresenta a forma de dentes esclerotinizados mostrando grande diversificação (McKitTricK, 1964). Klass (1997) filogeneticamente situou os blatelídeos como parafiléticos em relação aos blaberídeos e, embora GRANDCOLAS (1996) tenha sugerido a elevação taxonômica da subfamília Pseudophyllodromiinae à família, KLAss \& MeIER (2006) com base em estudos moleculares não consideraram que tais estudos tenham fornecido suporte para tal, mantendoa no táxon subfamília.

$\mathrm{O}$ gênero aqui descrito, com base na sua configuração geral, apresenta similaridade com espécies pertencentes aos gêneros Chorisoneura Brunner, 1865, Sorineuchora Caudell, 1927, Chorisoneurodes Princis, 1962 e Chorisoserrata Roth, 1998, os quais englobam espécies pequenas, delicadas com asas pouco nervuladas e bem espaçadas, geralmente transparentes, brilhosas, médio-apicalmente triangulares; a tégmina reticulosa e triângulo apical moderadamente desenvolvido. Aos dois primeiros se assemelha pela venulação da asa, e à Chorisoneurodes e Chorisoserrata pela placa subgenital assimétrica com estilos lamelares.

\section{MATERIAL E MÉTODOS}

Para a observação das placas genitais foi feita a retirada da extremidade do abdome, utilizando-se técnicas tradicionais de dissecção seguindo LOPES \& OLIVEIRA
(2000). A designação das peças genitais foi baseada nos conceitos propostos por RoTH (2003).

O material está depositado na coleção do Departamento de Entomologia do Museu Nacional, Universidade Federal do Rio de Janeiro (MNRJ).

\section{Chorisomaculata gen. nov.}

Espécie-tipo. Chorisomaculata manauensis sp. nov.

Coloração castanho-amarelada com manchas arredondadas de castanho-escuras a pretas espalhadas no pronoto e nas tégminas (Fig. 10). Forma geral lanceolada com tégminas apresentando textura fosca; pronoto elíptico; tégminas longas que ultrapassam em comprimento o ápice dos cercos; campo marginal amplo e longo, cerca da metade do comprimento do campo escapular, este último amplo e com veias em disposição oblíqua; campo discoidal levemente oblíquo com veias irradiadas; campo anal amplo, cerca da metade da largura da tégmina. Asa com campo costal e ápice dos ramos da radial levemente dilatado; triângulo apical desenvolvido e campo anal dobrado em leque; pernas espinhosas com o fêmur anterior (Fig. 4) na margem ântero-ventral com onze espinhos pequenos e dois apicais maiores e margem póstero-ventral com uma série de cinco espinhos espaçados maiores e um apical; fêmures médio e posterior com sete espinhos grandes e espaçados, um deles apical; espinho genicular presente; pulvilos em todos os artículos tarsais; unhas simétricas e simples; arólios pequenos; abdome com sétimo segmento modificado, proeminente ântero-medianamente e com um grupamento simétrico de cerdas longas na região mediana (Fig. 3); placa supra-anal pouco desenvolvida, ciliada e triangulóide (Fig. 5), sem reentrância mediana apical; cercos curtos e alargados; placa subgenital simétrica (Fig. 6), alargada no ápice, com projeções látero-apicais; estilos lamelares, arredondados apicalmente situados medianamente no ápice da placa. Projeção esclerotinizada desenvolvida, recoberta de espinhos e cerdas entre os estilos. 
Discussão. Chorisomaculata gen. nov. difere de Chorisoneurodes, Sorineuchora e Chorisoserrata por apresentar: unhas tarsais simples, simétricas; margem interocular não truncada (Fig. 1); sétimo segmento abdominal com modificação tergal (Fig. 3); pulvilos em todos os artículos tarsais e arólios pequenos. A coloração castanho-clara amarelada com pontuações que se encontram distribuídas em toda a sua área (Fig. 10), o tamanho dos cercos (Fig. 5), a configuração da placa subgenital (Fig. 6) mediano-apicalmente e dos estilos arredondados e lameliformes vêm reforçar a descrição como gênero novo.
Etimologia. O nome genérico é uma composição de Choriso, devido à similaridade com as espécies do gênero Chorisoneura e maculata, referente às manchas escuras nas tégminas.

\section{Chorisomaculata manauensis sp. nov.}

(Figs 1-10)

Etimologia. O nome da espécie refere-se à capital do estado do Amazonas.

Coloração castanho-clara, hialina. Cabeça com olhos negros com margem interna castanho-escura;
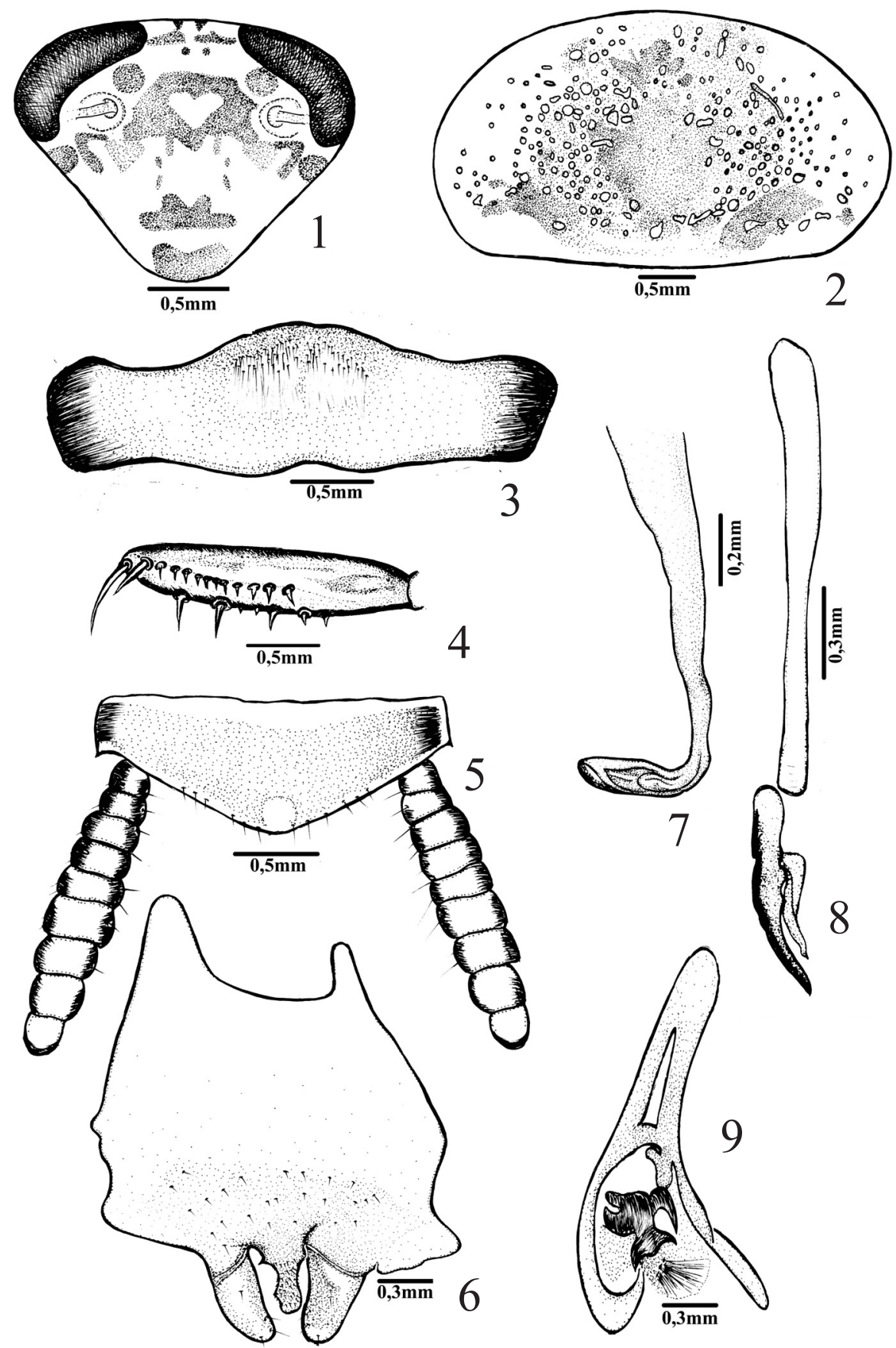

Figuras 1-9. Chorisomaculata manauensis sp. nov., holótipo o’: 1, cabeça, ventral; 2, pronoto, dorsal; 3, modificação abdominal do sétimo tergito; 4, espinhação nas margens ântero e póstero-ventral do fêmur anterior; 5, placa supra-anal, dorsal; 6, placa subgenital, ventral; 7, falômero direito, dorsal; 8, esclerito mediano, dorsal; 9, falômero esquerdo, dorsal. 
antenas e palpos castanho-claros com tomentosidade dourada. Fronte (Fig. 1) castanho-clara com nuances castanho-escuras, clípeo e labro castanho-escuros. Pronoto com pontuações castanho-escuras, espalhadas por toda a sua área (Fig. 10); disco central do pronoto (Fig. 2) castanho-amarelado, leitoso, com área central apresentando mancha castanho-escura concentrada. Base das coxas, base dos espinhos dos fêmures, manchas no dorso das tíbias e artículos apicais dos tarsos castanho-escuros. Tégminas com manchas escuras irregulares e esparsas.

Cabeça subtriangular, vértice levemente exposto sob o pronoto; espaço interocular amplo, cerca de dois terços da área que separa as bases das inserções antenais; ocelos bem marcados; antenas longas, ultrapassam o ápice do abdome.

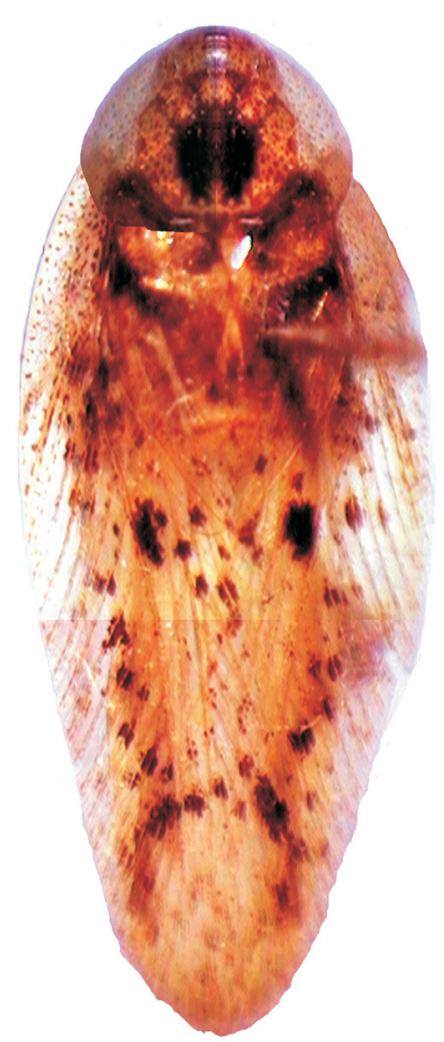

Figura 10. Chorisomaculata manauensis sp. nov., holótipo ơ: habitus, dorsal $(13 \mathrm{~mm})$.
Pronoto elíptico, convexo e transverso, com entorno arredondado e abas laterais amplas.

Abdome com modificação tergal (Fig. 3) distinta no sétimo segmento. Placa supra-anal (Fig. 5) triangular com ápice proeminente e cercos curtos. Placa subgenital (Fig. 6) com projeção esclerotinizada desenvolvida, recoberta de espinhos e cerdas entre os estilos. Falômero direito (Fig. 7) em forma de gancho, com pequena reentrância pré-apical com esclerotinização interna; esclerito mediano (Fig. 8) longo com L2d bífido, sendo o ápice em uma das extremidades membranoso e na outra esclerotinizado e afilado apicalmente, com espinhos diminutos no entorno; falômero esquerdo (Fig. 9) em forma de $\mathrm{Y}$ invertido, diferenciado com estruturas esclerotinizadas medianamente.

Dimensões (mm). Holótipo $\sigma^{\curvearrowright}$. Comprimento total 13,0; comprimento do pronoto 2,5; largura do pronoto 4,0; comprimento da tégmina 11,5; largura da tégmina 3,5.

Material-tipo. Holótipo o', BRASIL, Amazonas: Coari, rio Urucu, LUC.09, 4 51'56"'S, 65 04'56"W, 25.I-10.XI.1995, P. F. Buhrnhein cols.

Agradecimentos. Ao CNPq pela concessão da bolsa de pesquisador a SML.

\section{REFERÊNCIAS BIBLIOGRÁFICAS}

Beccaloni, G. W. 2007. Blattodea Species File Online. Version 1.2/3.3. Disponível em: 〈http://Blattodea.SpeciesFile.org> Acesso em: 20.05.2008.

GrandColas, P. 1996. The phylogeny of cockroach families: a cladistic appraisal of morpho-anatomical date. Canadian Journal of Zoology 74:508-527.

KLASS, K.-D. 1997. The external male genitalia and the phylogeny of Blattaria and Mantoidea. Bonner zoologische Monographien 42:1-341.

KLass, K.-D. \& Meier, R. 2006. A phylogenetic analysis of Dictyoptera (Insecta) based on morphological characters. Entomologische Abhandlungen 63(1-2):3-50.

Lopes, S. M. \& Oliveira, E. H. 2000. Espécie nova de Eublaberus Hebard, 1919 do Estado de Goiás, Brasil e notas sobre E. marajoara Rocha e Silva-Albuquerque, 1972 (Blaberidae, Blaberinae). Boletim do Museu Nacional, N. S., Zoologia 433: $1-5$.

McKittrick, F. A. 1964. Evolutionary studies of cockroaches Cornell University Agricultural Experiment Station Memoirs 389:1-197.

Rotн, L. M. 2003. Systematics and phylogeny of cockroaches (Dictyoptera: Blattaria). Oriental Insects 37:1-186. 